\title{
Sustainable Energy Consumption with Load Shape Characterization of Unmetered Food Vendors in a Campus Cafeteria Complex
}

\author{
Abdur-rahman A. Quadri ${ }^{1}$, Emmanuel O.B. Ogedengbe ${ }^{1}$ and Marc A. Rosen ${ }^{2}$ \\ 1 Energhx Research Group, Department of Mechanical Engineering, 353 Faculty of \\ Engineering, University of Lagos, Akoka-Yaba, Lagos, 101017, Nigeria; E-Mails: \\ ogedengbe@energhx.com (E.O.B.O.); dekunlerq@yahoo.com (A.A.Q.) \\ 2 Faculty of Engineering and Applied Science, University of Ontario Institute of \\ Technology, 2000 Simcoe Street North, Oshawa, ON, L1H 7K4, Canada; E-Mail: \\ marc.rosen@uoit.ca (M.A.R.)
}

\begin{abstract}
The electricity consumption patterns of food vendors within the University of Lagos 2001 Cafeteria complex on daily and seasonal bases as function of users' behavioral and load demands are characterized. This paper investigates the capability of using multivariable linear regression (MLR) and condition demand analysis (CDA) as methodologies to determine the consumption patterns of unmetered food vendors in a deregulated power system. These approaches can help in developing a unique sustainability model, based on food vendor's behaviour from the use of appliances in the cafeteria. It is anticipated that this model would enable automatic allocation of electricity consumption to unmetered food vendors. The profiles for individual food vendors, which contribute towards the aggregate load profile for the cafeteria complex, are characterized. The integration of this load-shape allocation model with the ongoing development of an alternative renewable power generation from food waste is capable of reducing peak-demand from the local grid.
\end{abstract}

Keywords: Multivariable linear regression, Condition demand analysis, Electricity consumption, Load shape 


\section{Introduction}

The scarcity of electricity in Nigeria has fostered significant research on characterizing and forecasting electrical loads in residential and commercial buildings. At a local system demand level, the University of Lagos is faced with the challenge of distributing its limited and inefficient supply from the electrical grid among various sectors of consumers, whose estimated demand is $8 \mathrm{MW}$. The load shape characterization describes how the food vendors use electricity at different hours of the day, days of the week and throughout the year. It also describes the total load of the 2001 Cafeteria as a whole in relation to the electricity supplied. Characterization of electricity use is a process which defines the use of electricity rather than attempting to predict its behaviour over time. Electricity characterization defines the method with which electricity is used in the cafeteria and relates this to environmental characteristics. Thus, an image is developed of each food vendor and the manner in which they consume electricity.

Several energy use models have helped in the energy characterization of consumers' demand in residential, commercial and industrial sectors. Generally, domestic electricity consumption is characterised based on top-down and bottom-up model approaches. Top-down models use estimates of total residential sector energy consumption to attribute energy consumption to characteristics of the housing sector. In other words, top-down models describe the energy system in terms of aggregate data collected at a high level based on demographics, housing statistics, historical data and related information to derive causal relationships between these and electricity consumption ${ }^{1,2}$. Bottom-up models, on the other hand, use data collected at an individual dwelling level to determine the relationships between household characteristics and electricity consumption ${ }^{1}$. The bottom-up approach has the capability of determining total energy consumption of the residential sector without relying on historical data.

For example, Baker and Rylatt ${ }^{3}$ used regression to determine a relationship between household characteristics and annual electricity consumption for 148 dwellings in two major cities in the United Kingdom. The facility characteristics that exhibited the greatest significance with respect to electricity consumption within the building include: floor area, occupancy, number of devices/appliances (e.g., televisions, personal computers, storage heaters) and number of showers per week. Parti and Parti ${ }^{4}$ pioneered the method and used 
monthly electricity bills over a yearly period and appliance ownership figures and a number of demographic variables to disaggregate electricity demand into sixteen different end-uses. This methodology showed the high significance of appliance ownership with respect to electricity consumption patterns. Leith et $\mathrm{al}^{5}$ applied a Gaussian process to forecast electricity system demand over a year in Ireland, and found that the Gaussian process performed better compared to an integrated seasonal autoregressive approach and a basic structural model. Richardson et $\mathrm{al}^{6}$ introduced a Markov-chain technique to generate synthetic active occupancy patterns based on surveys with respect to data indicating the time of use in the United Kingdom.

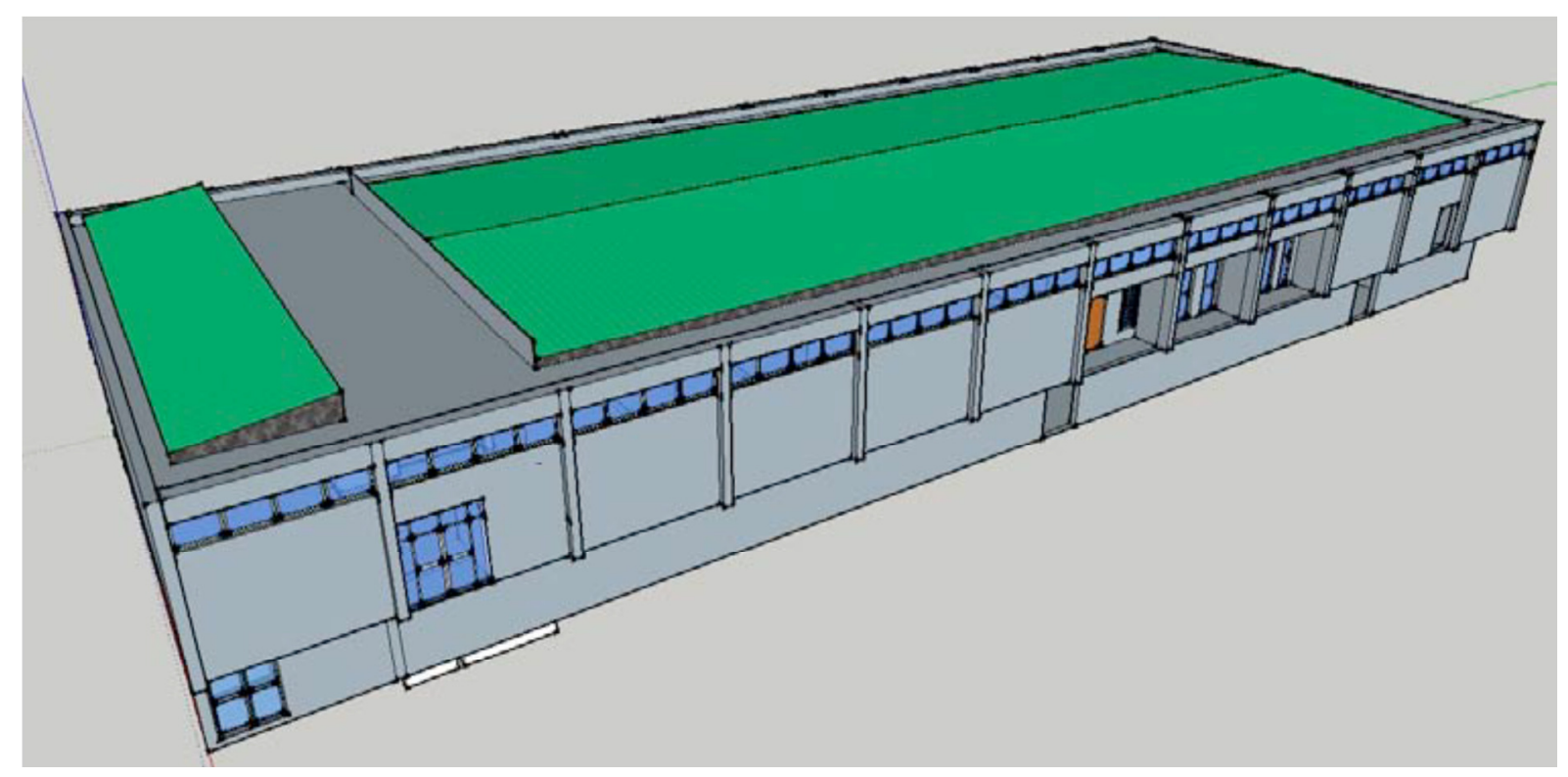

Figure 1. 2001 University Cafeteria Complex

Electricity distribution to homes and business is the final step in the electricity generation, transmission and distribution chain. As a result, a large amount of research has focussed on characterising and forecasting electrical demand in order to balance supply and demand. In this paper, we are faced with the problem of characterizing the load of unmetered food vendors. The objective of this research is, as a consequence, to propose a model that can help in developing a fair billing system for the food vendors, and to identify the amount of energy consumed in the cafeteria.

\section{Background}


The University of Lagos, Nigeria was founded in 1962. The Institution has built a reputation that endears it to many people from different ethnic groups within Nigeria. This has led to a continuing increase in the population of students as well as teaching and non-teaching staff, and an escalation in business opportunities for investors.

The catering business is vibrant at present due to the large population of students who depend on it for their daily meals. The 2001 Cafeteria is located at New Hall and is comprised of five hostels which accommodate about 3,000 students. The 2001 Cafeteria presently consumes four major forms of energy: electricity, charcoal, kerosene and gas. Of the four, electricity is used the most. Hence, an adequate supply of electricity to the cafeteria is important to the food vendors.

Few energy audits have been carried out at the University of Lagos to determine the load of appliances in the 2001 Cafeteria $^{7}$. This research differs from previous works in the area as it illustrates load profiles that reflect different patterns of electricity use within the 2001 Cafeteria. In addition, this work highlights the relationship between the 2001 Cafeteria, its customers and appliance characteristics to electricity usage within the cafeteria. This implies that each food vendor's electricity consumption profile can be completely identified based solely on the food vendor's characteristics. The thesis written by Kingsley ${ }^{7}$ and supervised by Dr E.O.B. Ogedengbe incorporated on energy audit of electrical appliance loads in the University cafeteria and investigated the feasibility of biogas supply from waste food. Ogedengbe et al. ${ }^{15}$ further provided a walk-through of the energy audit of the appliances that are installed in the cafeteria complex. The study also showed the advantage of developing and integrating a biogas production system within 2001 Cafeteria which would help in increasing the awareness regarding the potential for using renewable energy in the University.

The total energy consumption of the cafeteria $E C$ is determined as follows using regression analysis:

$$
E C=a_{0}+a_{1} X_{1 i}+a_{2} X_{2 i}
$$

Here, $a_{1}, a_{2}$ denote regression coefficients and $X_{1 i}, X_{2 i}$ the predictor variables which are used to identify the amount of energy consumed by lighting and energy appliances in the cafeteria. The study shows that the cafeteria produces enough food waste to the generate the required electricity and possibly export a supplement to the grid. 
Adelaja et al. ${ }^{8}$ surveyed energy consumption and demand in tertiary institutions, and concluded a need exists for proper control of energy consumption. The study also showed that improvements in metering systems and energy data processing and storage can help to ensure effective energy consumption. Also, Etiosa ${ }^{9}$ identified various ways of reducing energy consumption, highlighting technological and behavioural approaches as two means to attain effective use of energy.

Chanza et al. ${ }^{10}$ used a vector regression approach for forecasting hourly load profiles, and showed that domestic load profiles are seasonal with consumption peaks in mornings and evenings. They also demonstrated that 1) winter months exhibit high usage compared to other seasons and this domestic load is by far the most dominant profile shape that characterize the net energy from the distribution grid, and 2) to improve model accuracy, seasonal effects, weekday and weekend variations, holidays, weather and temperature need to be integrated into load forecasting models. The following step-by-step process was followed in forecasting load:

1. Construct hourly structural models for the given time series for each year.

2. Use these models to create a time series of parameters $\beta_{0}$ and $\beta_{1}$.

3. Use these time series to predict future values for $Y_{t}$.

The last step is performed using the equation:

$$
Y_{t}=\beta_{0}+\beta_{1} X_{t}+e_{t}
$$

where $Y_{t}$ is the dependant variable (domestic municipality demand), $X_{t}$ is the independent variable (total net system demand), $\beta_{0}$ is the intercept, $\beta_{1}$ is the slope and $e_{t}$ is the error term. In similar research, Alkan et al ${ }^{11}$ investigated one year of electricity consumption demand for residents living in Erzurum province using linear, quadratic and cubic spline regression models. This was accomplished using the following formulation:

$y_{t}=a_{0}+b_{0} X_{t}+b_{1} Z_{1 t}+b_{2} Z_{2 t}+b_{3} Z_{3 t}+e_{t}$

Here, $a_{0}$ denotes the constant of the model, $b_{0}, b_{1}, b_{2}$ and $b_{3}$ denote the coefficients of the slope of the model and $e_{t}$ denotes the error term. This regression model was used with the 
least squares method for estimating the daily electricity consumption of Erzurum province in 2011.

\section{Load Shape Characterization Techniques}

When comparing the unmetered food vendor's characteristics to electricity consumption patterns, statistical, regression and probabilistic methodologies are often useful. In developing a model to assist in the characterisation of the load from the unmetered food vendors, several factors influencing the food vendor's load have to be recognized. The main factors include seasonal variations, weekday variations, weather, temperature and calendar effects. These factors need to be considered in characterizing loads for unmetered food vendors. Knowledge of the expected energy use can assist in energy demand planning.

After reviewing a number of different approaches with their ability to characterise the load of each unmetered food vendor within the 2001 Cafeteria, the statistical regression method is proposed to have the ability to properly define the characteristics of appliances that influence electricity use in the 2001 Cafeteria. The following time series techniques were examined: Fourier transforms, Gaussian processes, neural networks, and fuzzy logic. These methods could not define the load shape characterisation of each food vendor because the methods are used for forecasting future load patterns. Clustering based approaches were also investigated, but could not define the load of each food vendor since it is not known.

\subsection{Conventional Regression Model}

Regression analysis is a statistical tool for the investigation of relationships between variables. It concentrates on the relationship between a dependent variable and one or more independent variables. For the present study, regression provides a method of determining each vendor's characteristics that have significant influence over electricity consumption across the day in the cafeteria. O'Doherty et $\mathrm{al}^{12}$ used data from a National Survey of Housing Quality and applied a Papke-Wooldridge generalised linear regression model to infer a relationship between appliance ownership and household electricity consumption. Regression analysis is widely used for predicting and forecasting load profiles. In this paper however, regression analysis is used in predicting the load profile of each vendor. 
Linear regression load profiles are models that apply a set of coefficients (i.e., regression coefficients) and independent variables whose values are used to predict the outcome of a dependent variable. In multivariable linear regression, there are several independent variables whose values are used to predict the outcome of a dependent variable (energy consumption). The general equation for multivariable linear regression follows:

$$
y(x)=\beta_{0}+\beta_{1} x_{1}+\beta_{2} x_{2}+\cdots \beta_{n} x_{n}+\epsilon
$$

Here, $y$ is the dependent variable (energy consumption), $\beta_{1}, \beta_{2}$ are the regression coefficients, which explain the influence of each independent variable on $y(x)$, and $\beta_{0}$ is a constant. Also, $x_{1}, x_{2} \ldots x_{n}$ are independent variables referring to the vendor's characteristics; these are investigated in relation to the dependent variable.

An alternative to the regression approach is conditional demand analysis (CDA), a method in which total electricity consumption is disaggregated into separate components by knowing the appliance holdings and total energy consumed within the cafeteria ${ }^{1}$. A regression analysis is then carried out on the data to generate a series of equations that, when combined, represent total energy end-use. Parti and Parti ${ }^{4}$ pioneered the method and used monthly electricity bills over a yearly period and appliance ownership figures and a number of demographic variables to disaggregate electricity demand into sixteen different end-uses. Aigner et al. ${ }^{13}$ furthered the CDA approach of Parti and Parti, by using twenty-four regression equations to estimate electricity consumption for each hour of the day. Bartels et al. ${ }^{14}$ developed a load forecasting model called DELMOD, which is a domestic end-use forecasting and simulation model. At half hourly intervals using CDA in New South Wales, Australia, electricity readings for up to sixteen different end-user were taken from a sample of 250 households over fifteen months. This model produced a number of average load profiles for each end-user and also provided a detailed representation of the appliance stock and socio-demographic characteristics.

\subsection{Combined MLR-CDA Model}

From the above analysis, we propose two bottom-up models for each vendor's load shape characterization. The structures of the models are given in Fig. 2. The first model defines how the load shape characterization of unmetered food vendors can be estimated using multivariable linear regression while the second model describes how the load shape 
characterization of unmetered food vendors can be estimated using Conditional Demand Analysis.

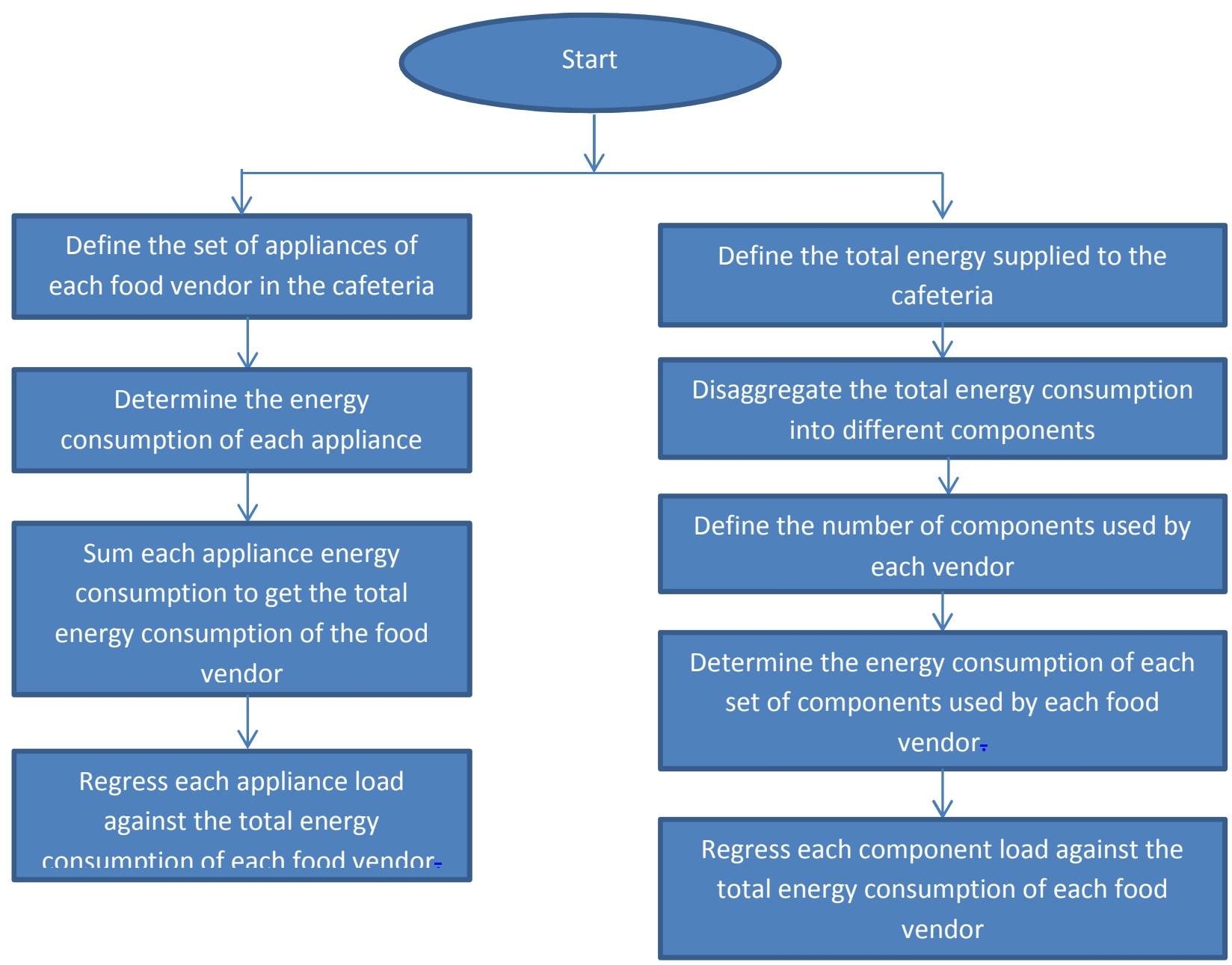

\section{Figure 2. Proposed Model}

\subsubsection{Methodology for Model One}

\section{Defining the sets of appliances used in the cafeteria}

This step involves collecting the list of appliances of each food vendor and determining ratings for each appliance.

For appliances like refrigerator, which have discontinuous power consumption, the rating changes from time to time due starting and stopping. Determining the ratings of this appliance involves the use of ammeter. 


\section{Determining the energy consumption of each appliance}

The hourly electrical usage of electrical appliances of each food vendor depends on client patronage, which explains why energy consumption of the food vendors is higher on weekdays than weekends. The energy consumed can be calculated as follows:

$$
Q=\text { Energy rating } * \text { Hours of use } * n
$$

where $Q$ is the total energy consumed in $\mathrm{kWh}$ and $n$ is the quantity of each appliance.

For appliances with discontinuous power consumption, the total power consumed, $P$, is calculated by multiplying the ammeter reading by the rated voltage $(230 \mathrm{~V})$.

$$
P[\text { watt }]=\text { Ammeter reading }[\text { ampere }] * \text { Rated voltage }[\text { volt }]
$$

\section{Sum all appliance electrical consumptions}

To determine the electrical consumption of each food vendor, we sum the energy consumption of all the appliances, as follows:

$$
y=\sum Q_{1}+Q_{2}+Q_{3} \ldots+Q_{n}
$$

\subsubsection{Methodology for Model Two}

\section{Defining the total energy supplied to the cafeteria-}

According to Kingsley ${ }^{7}$, the daily energy supplied, $X$, from the grid is $2148 \mathrm{KWh}$.

\section{Disaggregating the total energy consumption into different components}

Separating the total electricity consumption into three components (lightning, refrigeration and appliance use), we can write:

$$
X=L+R+E
$$

where $L, R, E$ denote total lightning, total refrigeration, total electrical appliances respectively.We can express $L$ as:

$$
L=q_{1}+q_{2}+\ldots q_{n}
$$


where $q_{1}, q_{2}, q_{n}$ represents the quantity of lightning for vendor one, vendor two and so on up to vendor n, i.e.,

$$
X=\sum_{i=1}^{n} y_{i}=\sum_{i=1}^{n}\left(L_{i}+R_{i}+E_{i}\right)
$$

$y_{i}$ is the total consumption for vendor $i$.

\section{REFERENCES}

${ }^{1}$ F. McLoughlin "Characterising Domestic Electricity Demand for Customer Load Profile Segmentation” Dublin Institute of Technology, fintan.mcloughlin@dit.ie.

${ }^{2}$ M. Howley, E. Dennehy, B. Ó. Gallachóir, and M. Holland, "Energy in Ireland 1990 - 2011,” Dublin, 2012.

${ }^{3}$ K. J. Baker and R. M. Rylatt, "Improving the prediction of UK domestic energy demand using annual consumption-data," Applied Energy, vol. 85, no. 6, pp. 475-482, Jun. 2008.

4 M. Parti and C. Parti, "The Total and Appliance-Specific Conditional Demand for Electricity in the Household Sector," The Bell Journal of Economics, vol. 11, no. 1, p. 309, 1980

${ }^{5}$ D. J. Leith, M. Heidl, and J. V Ringwood, "Gaussian Process Prior Models for Electrical Load Forecasting," 8th International Conference on Probabilistic Methods Applied to Power Systems, 2004.

6 I. Richardson, M. Thomson, and D. Infield, A high-resolution Domestic Building Occupancy model for Energy Demand Simulations, Energy and Buildings 40 (2008) 15601566.

7 E. Kingsley, "Energy audit of electrical appliance loads in University Cafeteria with feasibility of Biogas supply from Wastefood. A case study of the 2001 cafeteria", B.Sc Thesis, Department of Mechanical Engineering, University of Lagos, February 2014.

${ }^{8}$ A.O Adelaja, O.Damisa, S.A. Oke, A.B Ayoola and A.O. Ayeyemitan,"A Survey on the Energy Consumption and Demand in a Tertiary Institution", Maejo International Journal of Science and Technology, 2008,2(02), 331-3444.

${ }^{9}$ U. Etiosa, "Energy Efficiency Survey in Nigeria, A Guide for Development Policy and Legislation", community Research and Development Centre, 2009. 
${ }^{10}$ M. Chanza, P. Ramjith, G. Van Harmelen, "Forecasting Domestic Hourly Load Profiles Using Vector Regressions" Enerweb, Megawatt Park, Sunninghill, Johannesburg, South Africa.

11 Ö. Alkan, A. Genç, E. Oktay \& A. Kemal and K. Çelik "Electricity Consumption Analysis Using Spline Regression Models: The Case of a Turkish Province" Faculty of Economics and Administrative Sciences, Department of Econometrics, Atatürk University, Erzurum, Turkey. Faculty of Sciences, Department of Statistics, Selçuk University, Konya, Turkey. Faculty of Economics and Administrative Sciences, Department of Business Administration, Erzurum, Turkey.

12 J. O'Doherty, S. Lyons, and R. S. J. Tol, "Energy-using appliances and Energy saving features: Determinants of ownership in Ireland," Applied Energy, vol. 85, no. 7, pp. 650-662, Jul. 2008 .

${ }^{13}$ C. Aigner, C. Sorooshian,_and P. Kerwin-, "Conditional Demand Analysis for estimating residential end-use profiles,” The Energy Journal, vol. 5, pp. 81-97,_1984.

${ }^{14}$ R. Bartels, R., Fiebig, D.G., Garben, and M., Lumsdaine, “An_-_End-Use Electricity load Simulation Model (DELMOD),” Utilities Policy, vol. 2, no. 1, pp. 71-82, 1992.

15 E.O.B. Ogedengbe, E. Kingsley, R.U. Eteure and M.A. Rosen, "Feasibility Study of Cafeteria Energy Demand with Integration of a Downdraft Bio-digester System", 10th International Energy Conversion Engineering Conference, 30 Jul - 1 Aug 2012, Atlanta, Georgia 